ISSN 0103-9954

\title{
CRESCIMENTO DE ESPÉCIES NATIVAS DE UMA FLORESTA ESTACIONAL DECIDUAL/OMBRÓFILA MISTA DO RIO GRANDE DO SUL
}

\section{GROWTH OF NATIVE SPECIES OF THE DECIDUOUS/DENSE TROPICAL FOREST OF RIO GRANDE DO SUL}

\author{
Peter Spathelf $^{1} \quad$ Rute Berger $^{2} \quad$ Sandro Vaccaro $^{2}$ Helio Tonini ${ }^{2}$ Geedre Adriano Borsoi ${ }^{2}$
}

\section{RESUMO}

Com uma abordagem retrospectiva, foi estudado o crescimento da caúna-da-serra (Ilex brevicuspis Reissek.), cocão (Erythroxilum deciduum), tarumã-de-espinho (Cytharexylum montevidense Sprenger) e capororoca (Rapanea ferruginea (Ruiz \& Pavon) Mez), nativas da Floresta Estacional Decidual/Floresta Ombrófila Mista de Santa Maria - RS. Foi feita a análise de tronco e a medição de anéis anuais de cada espécie estudada. Com esses dados foi avaliada a tendência de crescimento em volume comercial, o incremento do volume comercial em porcentagem e o fator de forma comercial em função do diâmetro à altura de 1,3 m (DAP). Para o ajuste dos dados obtidos, foram testados cinco modelos diferentes. Revelou-se que, com todas espécies, um polinômio de segundo grau mostrou o melhor ajuste no caso do volume comercial e do fator de forma comercial. O incremento em volume comercial anual percentual foi melhor ajustado por um modelo exponencial, também para cada espécie analisada. Observou-se uma acumulação significativamente diferente do volume sobre o diâmetro das espécies. O tarumã e o cocão mostram uma acumulação rápida em volume, enquanto que a caúna e a capororoca crescem menos rapidamente. Isso é correlacionado com os fatores de forma, nos troncos mais cilíndricos, no caso do tarumã e do cocão. O incremento em volume comercial anual percentual varia entre a faixa de mais de $100 \%$ no início do processo de crescimento e abaixo de $10 \%$ no final do crescimento estudado.

Palavras-chave: Análise de tronco, espécies nativas, Rio Grande do Sul.

\begin{abstract}
The tree species caúna-da-serra (Ilex brevicuspis Reissek.), cocão (Erythroxilum deciduum), tarumã-de-espinho (Cytharexylum montevidense Sprenger) e capororoca (Rapanea ferruginea (Ruiz \& Pavon) Mez), native in the deciduous seasonal forest / dense tropical forest of Santa Maria were studied using a retrospective analysis. A stem analysis was performed of each species, measuring annual growth rings. Volume growth, commercial form factor and the annual percentual increment of commercial volume were analyzed according to growth at diameter at breast height. For modelling purposes 5 different equations were tested. It could be shown that a polynome of second

1. Engenheiro Florestal, Dr., Professor Visitante (Programa de Intercâmbio DAAD/CAPES), Departamento de Ciências Florestais, Centro de Ciências Rurais, Universidade Federal de Santa Maria, CEP 97105-900, Santa Maria (RS). peter.spathelf@fdtue.bwl.de

2. Engenheiro Florestal, MSc.; Programa de Pós-Graduação em Engenharia Florestal, Centro de Ciências Rurais, Universidade Federal de Santa Maria, CEP 97105-900, Santa Maria (RS)
\end{abstract}


degree was best adjusted to the growth of commercial volume and commercial form factor while annual percentual increment of commercial volume showed best fit with an exponential function. A significantly different accumulation of volume could be found concerning the different species which were studied. While tarumã and cocão show a rapid accumulation in growth, caúna and capororoca grow more slowly. This is correlated with more cylindric stems in the case of tarumã and cocão. The annual percentual increment of commercial volume moves between the range of more than $100 \%$ at the beginning of the growth process and below $10 \%$ at the end of the studied growth period.

Key words: Stem analysis, native species, Rio Grande do Sul.

\section{INTRODUÇÃO}

O Estado do Rio Grande do Sul, nos últimos 50 anos, delapidou suas maiores e mais importantes reservas naturais de madeira, restando atualmente áreas insignificantes geralmente localizadas em locais de difícil acesso. $\mathrm{O}$ desmatamento indiscriminado trouxe além de problemas ecológicos, como a erosão e perda de fertilidade do solo, a falta de madeira que é atualmente suprida quase que, exclusivamente, pelo reflorestamento com espécies exóticas.

Uma das maneiras de se avaliar crescimento e produtividade é por meio de inventários contínuos com instalação de parcelas permanentes; porém, o inconveniente é o grande período necessário para a obtenção dos dados. Entretanto, quando a espécie de interesse apresenta anéis de crescimento observáveis, a técnica de análise de tronco permite recompor o crescimento passado de uma árvore de maneira relativamente rápida.

Com base na análise de tronco, pode-se avaliar a produtividade de um sítio, o crescimento e qualidade de determinado indivíduo em diferentes períodos de sua vida. Pode-se também estudar o fator de forma do tronco (FINGER, 1992).

A avaliação da potencialidade econômica e silvicultural de uma determinada espécie deve abranger além das suas características ecológicas, o estudo de seu crescimento e produtividade em um dado sítio. O conhecimento sobretudo do incremento volumétrico das espécies comercializáveis numa floresta pode servir como base para determinar a taxa de corte de madeira comercial num plano de manejo.

Em vista disso, o presente estudo tem os seguintes objetivos principais:

a) Descrever o crescimento em diâmetro e volume comercial e o fator de forma comercial.

b) Comparar o comportamento do crescimento das espécies estudadas.

\section{REVISÃO BIBLIOGRÁFICA}

A seguir é apresentada uma discussão dendro-ecológica das espécies estudadas: 


\section{Caúna-da-serra (Ilex brevicuspis Reissek.)}

Segundo EDWIN \& REITZ (1967), a caúna-da-serra (Ilex brevicuspis) apresenta-se sob forma de árvore ou arbusto perenifoliado, alcançando até $25 \mathrm{~m}$ de altura, porém mais comumente de 10-20m, e até $80 \mathrm{~cm}$ de diâmetro, sendo mais encontrada entre $30-70 \mathrm{~cm}$. Possui tronco cilíndrico, quase-reto, ramificação racemosa, formando copa alongada, paucifoliada, com folhagem verde- escura. A espécie floresce intensamente todos os anos, produzindo abundantes frutos com sementes férteis (REITZ et al., 1988).

No Rio Grande do Sul, é vastamente difundida pelos sub-bosques dos pinhais do Planalto, onde é bastante freqüente. De modo menos freqüente, ocorre na Floresta do Alto Uruguai, o que é confirmado por VACCARO \& LONGHI (1995), e na Depressão Central, alcançando o Escudo Rio-grandense (REITZ et al., 1988). Em análise de um remanescente de Floresta Ombrófila Mista, na região de Santa Maria (RS), LONGHI et al. (1996) observaram que tal espécie, conjuntamente com outras, predomina no estrato arbóreo superior, rivalizando em altura com as araucárias.

Em Santa Catarina é encontrada quase que, exclusivamente, no planalto, sendo característica nesse local. No Brasil, ocorre ainda no Paraná e Rio de Janeiro; na Argentina, em Missões.

A madeira da espécie é considerada de boa qualidade, apresentando uma cor bege-clara. Os limites dos anéis são bem-visíveis, com a madeira tardia representando a maior parte da área do anel.

\section{Cocão (Erythroxilum deciduum)}

A origem do nome do gênero Erythroxilum vem do idioma Grego, onde Erythros significa vermelho e Xylom significa madeira, em alusão à casca avermelhada de algumas espécies. Existem nove espécies que ocorrem no RS e há registros da ocorrência do Erythroxilum deciduum nos estados do Piauí, Bahia, Mato Grosso, Goiás, Minas Gerais, Rio de Janeiro, São Paulo, Paraná e Santa Catarina, bem como no Peru, Paraguai e Argentina. SCHULZ (1907), levando em consideração aspectos morfológicos como: forma, textura, flores e brilho das folhas, afirmou ter encontrado duas variedades para a espécie, a Opacum e Brevifolium.

Porém, AMARAL JR. (1980) afirma que essas variações são ambientais e por si só não justificam a criação dessas variedades. SOBRAL (1981) também observou dois padrões foliares distintos, sendo que uma forma ocorria em todo o estado ao norte da Depressão Central e outra ficava mais restrita a essa região.

O autor destacou que, dificilmente, os indivíduos pertencentes a pontos extremos entre essas duas formas poderiam ser classificados como sendo de uma mesma espécie. Entretanto, observou a existência de indivíduos intermediários entre uma forma e outra. Segundo AMARAL JR. (1980) essa espécie se apresenta com alturas que vão de 4 a 10 m e diâmetros de 20 a $40 \mathrm{~cm}$ à altura do peito.

O tronco pode ser reto ou tortuoso com uma casca externa cinza parda, lembrando a do branquilho (Sebastiania klotzchiana), e uma casca interna róseo-clara com 4 a $5 \mathrm{~mm}$ de espessura nas arvoretas mais desenvolvidas. Apresenta madeira vermelha quando seca, com anéis anuais bem- visíveis. A madeira é usada para fins de construção civil, cabos de ferramenta e lenha.

A espécie floresce de agosto a janeiro e frutifica de setembro a fevereiro, sendo que o fruto é

Ciência Florestal, v. 11, n. 2, 2001 
uma drupa vermelha quando madura, com 8 a $13 \mathrm{~mm}$ de comprimento e 4 a 5 mm de diâmetro.

Apesar da falta de informações e inexistência de coletas regulares em algumas regiões brasileiras, a espécie tem uma distribuição conhecida bastante ampla, sendo que o seu limite meridional se encontra nas regiões de baixa altitude próximo a Porto Alegre e em Corrientes na Argentina.

O cocão habita preferencialmente as matas de araucária, matas de galeria, capões e capoeiras, também ocorrendo em restingas e matas costeiras. Segundo SOBRAL (1990), a espécie pode ser encontrada nos mais variados ambientes, desde o interior das matas, beira de rios e regiões alagadiças, até campos e encostas de morros pedregosos, em zonas de solo muito pobre e permanentemente expostas ao sol e ventos.

\section{Tarumã-de-espinho (Cytharexylum montevidense Sprenger)}

O tarumã-de-espinho, da família das Verbenáceas (Verbenaceae), é uma árvore decidual de 20 a $25 \mathrm{~m}$ de altura e 50 a $80 \mathrm{~cm}$ de diâmetro. Apresenta vasta dispersão através das florestas latifoliadas do Alto Uruguai e na fralda da Serra Geral do Escudo Rio-Grandense, tendo uma distribuição bastante esparsa e, por vezes, bastante rara. A espécie prefere os solos úmidos e profundos das planícies aluviais, dos vales ou início das encostas. De modo geral, na floresta densa, encontram-se apenas exemplares plenamente desenvolvidos, ao passo que na floresta mais aberta, sua regeneração parece efetuar-se de forma mais regular. Trata-se possivelmente de árvore rara que, no ciclo climático atual, se encontra em adiantada fase de substituição, tendo pertencido às espécies pioneiras. Freqüentemente é encontrado nas florestas de galeria dos afluentes do rio Santa Maria.

As sementes podem ser colhidas nas próprias árvores ou por meio da coleta dos frutos caídos no chão. As sementes, após a coleta, suportam um armazenamento de até três meses, com a manutenção do poder germinativo. As sementes logo após serem colhidas devem ser retiradas dos frutos, mediante maceração de lavagem em água corrente para retirar a polpa carnosa.

A semeadura pode ser feita em canteiros, para a produção de raiz nua ou para repicar, ou ainda diretamente em embalagens individuais (MAIXNER \& FERREIRA 1978).

A madeira é branca e resistente e pode ser usada para obras internas, carpintaria, lenha e carvão (SANCHOTENE, 1985). O lenho tardio como limite do anel é nitidamente visível.

\section{Capororoca (Rapanea ferruginea (Ruiz \& Pavon) Mez)}

A espécie Rapanea ferruginea (Ruiz \& Pavon) Mez, da família das Myrcináceas, é uma espécie pantropical, com centro de dispersão no Brasil. Sua distribuição estende-se até a Bolívia, México, Argentina (nordeste), Paraguai (leste) e Uruguai. No Brasil, ocorre nos estados da Bahia (Chapada da Diamantina e Morro do Chapéu), Espírito Santo, Rio de Janeiro, Minas Gerais (nordeste e centro), São Paulo, Paraná, Santa Catarina e Rio Grande do Sul, aparecendo em quase todas as formações florestais em sua região de ocorrência (CARVALHO, 1994, SANCHOTENE, 1985).

No Rio Grande do Sul, distribui-se por quase todas as regiões fitogeográficas, sendo 
encontrada nas capoeiras das encostas da Floresta Ombrófila Densa, desde Torres à Maquiné; nas matas de Restinga da Planície Costeira, nas florestas estacionais do Alto Uruguai, Depressão Central, Encosta Inferior do Nordeste e Serra do Sudeste; na Floresta Ombrófila Mista dos Campos de Cima da Serra e na Matinha Nebular junto aos "canyons" dos Aparados da Serra.

Popularmente, é conhecida como capororoca, do tupi-guarani caá-pororoca que significa "árvore-que-estala". Também é denominada de azeitona-do-mato (SP, RJ, MG) e canelón-blanco (Argentina e Uruguai).

O sistema reprodutivo dessa espécie é dióico, a folhagem é persistente, a polinização é anemofílica e a dispersão de sementes do tipo zoocórica. Pode ocorrer em solos arenosos, solos rasos e pobres bem como em solos profundos e férteis e em várzeas e até banhado. Tolera regiões com distribuição sazonal da chuvas bem como geadas.

Os frutos maduros, produzidos anualmente em grande quantidade e com alto poder de germinação, servem de alimento para sabiás, jacus e muitas outras aves.

A madeira tem pouca durabilidade. Serve para obras internas, esteios, lenha e carvão.

\section{MATERIAL E MÉTODO}

Este trabalho foi realizado na Barragem de Val de Serra, no município de Itaára, a uma distância de, aproximadamente, $25 \mathrm{~km}$ da cidade de Santa Maria.

A área em estudo pertence a um tipo de cordão florestal ciliar da Fralda da Serra Geral e localiza-se numa altitude de, aproximadamente, $450 \mathrm{~m}$. O remanescente florestal encontra-se na interseção de duas coxilhas, formando um relevo de pequeno vale, com um córrego passando pela cota altimétrica mais baixa. As árvores-amostras estavam localizadas a menos de cinco metros do córrego.

Esta floresta ciliar pode ser classificada fitogeograficamente como um ecótono entre a Floresta Estacional Decidual e a Floresta Ombrófila Mista. A maioria das espécies são preferenciais da floresta estacional, porém, regionalmente, observa-se a presença de espécie preferenciais e exclusivas da floresta de pinhais, como o próprio pinheiro, o podocarpus e a murta.

Há indicações de que o fragmento sofreu, no passado, uma pressão antrópica. Acredita-se que houve a remoção das árvores de valor econômico, pois indivíduos de Araucaria angustifolia, característicos na região, não foram encontrados no local. Além do mais, é nitidamente visível a pressão pecuária sobre a regeneração natural da floresta.

O solo pertence à unidade de mapeamento Charrua, sendo do tipo litólico eutrófico (pela proximidade do córrego), com diversos afloramentos rochosos e acentuada declividade. Em consequência do material erodido das vertentes das coxilhas e pela origem da rocha matriz - Rochas Efusivas Básicas da Formação Serra Geral - o solo deve ser fértil. 
A região apresenta um clima do tipo Cfa, de acordo com a classificação climática de Köppen (MORENO, 1961). A precipitação média anual está em torno de $1691 \mathrm{~mm}$ e a temperatura média anual é de $19,2^{\circ} \mathrm{C}$.

No remanescente florestal descrito, foi escolhida uma árvore dominante de cada espécie florestal (veja revisão bibliográfica), quatro árvores no total, para análise de tronco. As árvores- amostra foram consideradas economicamente interessantes quanto ao manejo das florestas nativas da região. A derrubada das árvores foi feita com o auxílio de uma motosserra, retirando-se posteriormente fatias transversais em diferentes alturas, na base, ao dap e em posições superiores até a altura comercial do tronco totalizando 4 fatias por árvore. No momento da coleta, retirou-se material para a confecção de excicatas para posterior comprovação botânica.

As fatias coletadas foram secadas ao ar, à sombra em local bem-arejado. Posteriormente, sofreram lixamento, com o objetivo de tornar os anéis mais visíveis e facilitar a operação de marcação dos eixos e medição dos anéis. A marcação dos eixos para a medição seguiu as recomendações de Prodan apud FINGER (1992). Iniciou-se com a marcação do maior raio da seção, tomando-se a medula como centro. Com base no maior raio, foram marcados outros dois raios, formando um ângulo de $45^{\circ}$ com o maior raio, e deles projetados outros dois em sentidos opostos. Quando a visualização dos anéis não estava bem definida, umedecia-se a fatia para melhor realce do contraste entre lenho primaveril e outonal.

Os valores de crescimento, para cada árvore, em cada fatia e raio, foram obtidos considerando-se a distância do anel da casca à medula. A largura dos anéis de crescimento foi medida com auxílio do aparelho LINTAB com uma precisão de 1/100 milímetro.

Consideraram-se os anéis como anuais, dadas às condições climáticas locais. A região apresenta duas estações distintas, em que ocorre um período de baixa atividade cambial (inverno), ocasionando o surgimento de lenho tardio visível para as espécies estudadas. Providos dos valores de diâmetro em cada idade nas diferentes alturas da árvore, obtiveram-se os seguintes resultados: incremento corrente anual em diâmetro e volume; volume comercial; incremento em volume anual percentual; e fator de forma.

O volume comercial foi calculado pela cubagem anual das seções entre as fatias, pelo método de SMALIAN (veja FINGER, 1992). Com a relação do volume comercial com o volume de um cilindro de referência à altura do peito, obteve-se o fator de forma comercial. Para ajustar os dados, foram testados os seguintes modelos:

1) $y=b_{0} x^{b 1}$

2) $y=b_{0} e^{b 1 x}$

3) $y=b_{0}+b_{1} x+b_{2} x^{2}$

4) $y=b_{0}+b_{1} \ln x$

5) $y=b_{0}+b_{1} x$

Em que: $\mathrm{y}=$ variável dependente; $\mathrm{x}=$ variável independente (diâmetro); $\mathrm{e}=$ base logaritmo neperiano; $\ln =$ logaritmo neperiano $; b_{0}, b_{1}$ e $b_{2}=$ coeficientes angulares.

O emprego da idade, como variável independente em modelos para árvores individuais, em florestas inequiâneas heterogêneas, não é recomendável. $\mathrm{O}$ diâmetro à altura do peito (DAP) pode 
ser visto como substituto da idade nesses tipos de florestas (MITSCHERLICH, 1952). Para estabelecer taxas de corte num plano de manejo baseado em sistemas silviculturais com diâmetro mínimo de corte (LAMPRECHT, 1990), o conhecimento do incremento das árvores com diferentes dimensões é muito útil.

Os modelos foram testados utilizando o pacote estatístico SAS (Statistical Analysis System). $\mathrm{O}$ critério de seleção do modelo ótimo foi baseado nas estatísticas $\mathrm{R}^{2}$ (coeficiente de determinação), $\mathrm{S}_{\mathrm{yx}}$ (erro-padrão da estimativa) e na análise de resíduos.

\section{RESULTADOS E DISCUSSÃO}

Os resultados estatísticos do ajuste das funções testadas para a espécie caúna-da-serra são mostrados na Tabela 1. O modelo 3 (polinômio de segundo grau) mostra o melhor ajuste para o

TABELA 1: Caúna-da-serra - parâmetros estatísticos dos modelos estudados para estimar o volume comercial, o fator de forma comercial e o incremento volumétrico percentual em função do DAP (os modelos com melhor ajuste são marcados com asterisco).

\begin{tabular}{|c|c|c|c|c|c|c|}
\hline \multirow{2}{*}{$\begin{array}{c}\text { N. } \\
\text { mod. }\end{array}$} & \multirow[t]{2}{*}{ Variável dependente } & \multicolumn{3}{|c|}{ Coeficientes } & \multirow[t]{2}{*}{$\mathrm{R}^{2}$} & \multirow[t]{2}{*}{ Syx } \\
\hline & & $\mathrm{b}_{0}$ & $\mathrm{~b}_{1}$ & $\mathrm{~b}_{2}$ & & \\
\hline \multirow[t]{3}{*}{1} & $\operatorname{vol}_{\mathrm{c}}$ & 0,0002 & 2,2571 & & 0,9981 & 0,06568 \\
\hline & $\mathrm{ff}_{\mathrm{c}}$ & 0,3342 & 0,2571 & & 0,8709 & 0,09288 \\
\hline & ivol\% * & 80,199 & $-1,0508$ & & 0,9758 & 0,15495 \\
\hline \multirow[t]{3}{*}{2} & $\operatorname{vol}_{\mathrm{c}}$ & 0,0003 & 0,4856 & & 0,8252 & 0,90089 \\
\hline & $\mathrm{ff}_{\mathrm{c}}$ & 0,3423 & 0,0583 & & 0,8005 & 0,11550 \\
\hline & ivol\% & 69,192 & $-0,2328$ & & 0,8181 & 0,42528 \\
\hline \multirow[t]{3}{*}{3} & $\operatorname{vol}_{\mathrm{c}} *$ & 0,001 & $-0,0011$ & 0,0005 & 0,9994 & 0,00061 \\
\hline & $\mathrm{ff}_{\mathrm{c}} *$ & 0,2492 & 0,0635 & $-0,0026$ & 0,9553 & 0,02475 \\
\hline & ivol\% & 141,2 & $-34,7353$ & 2,0248 & 0,6155 & 32,9386 \\
\hline \multirow[t]{3}{*}{4} & $\mathrm{vol}_{\mathrm{c}}$ & 0,0197 & $-0,0072$ & & 0,5810 & 0,01573 \\
\hline & $\mathrm{ff}_{\mathrm{c}}$ & 0,1157 & 0,3343 & & 0,8821 & 0,03970 \\
\hline & ivol\% & $-48,452$ & 106,63 & & 0,7497 & 26,2413 \\
\hline \multirow[t]{3}{*}{5} & $\mathrm{vol}_{\mathrm{c}}$ & 0,0059 & $-0,143$ & & 0,9135 & 0,00715 \\
\hline & $\mathrm{ff}_{\mathrm{c}}$ & 0,0274 & 0,3374 & & 0,8825 & 0,03962 \\
\hline & ivol\% & $-8,13$ & 82,612 & & 0,3604 & 41,9496 \\
\hline
\end{tabular}

Em que: vol $_{\mathrm{c}}=$ volume comercial; $\mathrm{ff}_{\mathrm{c}}=$ fator de forma comercial; ivol $\%=$ incremento volumétrico percentual; $\mathrm{R}^{2}=$ coeficiente de determinação; Syx = erro-padrão da estimativa; $b_{0}, b_{1}, b_{2}=$ coeficientes angulares.

volume comercial e o fator de forma comercial como variável dependente, ambas com um coeficiente de determinação maior do que 0,95, e um erro-padrão de estimativa pequeno. No caso do incremento em volume anual percentual o melhor modelo foi o modelo 1 , também com coeficiente de determinação maior de 0,95 e o menor erro padrão de estimativa.

$\mathrm{O}$ volume comercial do tronco desenvolve-se de uma forma exponencial com o crescimento diamétrico. Em contrapartida, com aumento do diâmetro o incremento anual percentual cai, 
conforme esperado, de valores de acima de 200 para ao redor de $5 \%$. Esse comportamento da diminuição da taxa de crescimento com o aumento do tamanho de um organismo é, segundo o biólogo britânico Medawar apud ZEIDE (1993), uma lei da natureza. O fator de forma comercial se movimenta entre a faixa de 0,3 e 0,6 .

As Figuras 1 a 3 mostram o comportamento do volume comercial, fator de forma comercial e o incremento em volume comercial anual percentual em função do diâmetro. Na Figura 4 observa-se o desenvolvimento do DAP sobre a idade a altura do peito (sem ajuste). Conforme os dados obtidos, nos primeiros 40 anos, o diâmetro segue uma reta.

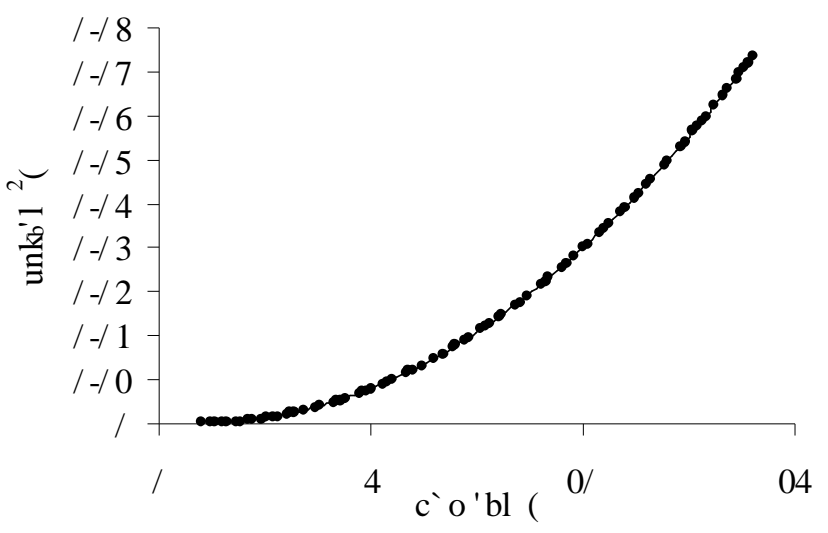

FIGURA 1: Desenvolvimento do volume comercial ( $\operatorname{vol}_{\mathrm{c}}$ ) em função do DAP, da caúna-da-serra.

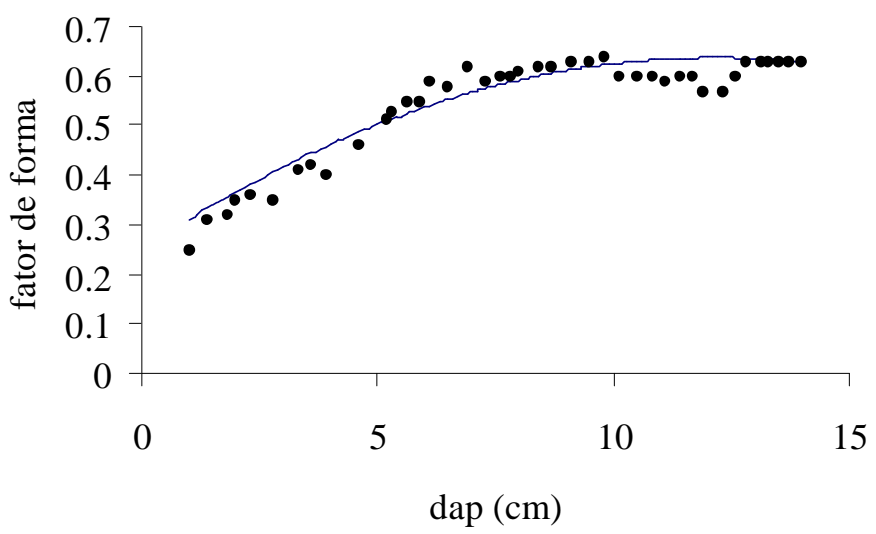

FIGURA 2: Desenvolvimento do fator de forma comercial em função do DAP, da caúna-da-serra. 


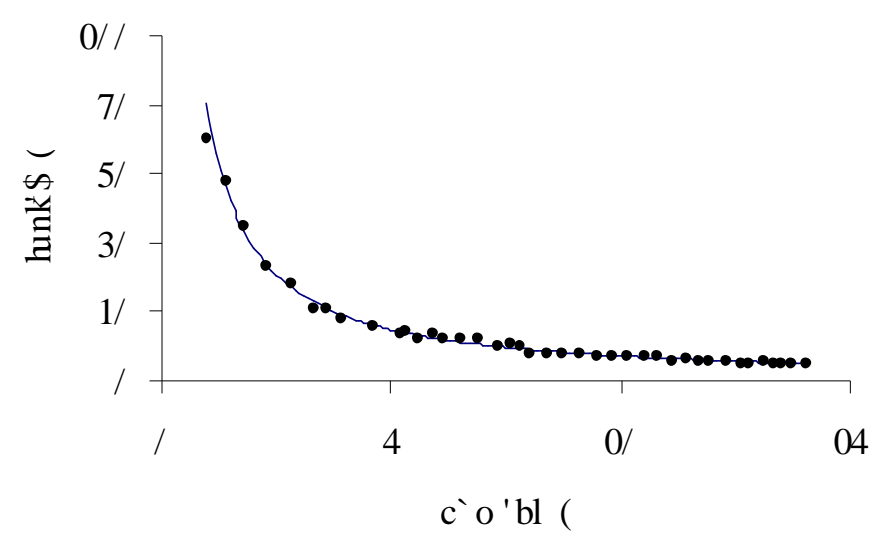

FIGURA 3: Desenvolvimento do incremento em volume comercial anual percentual (ivol) em função do DAP, da caúna-da-serra.

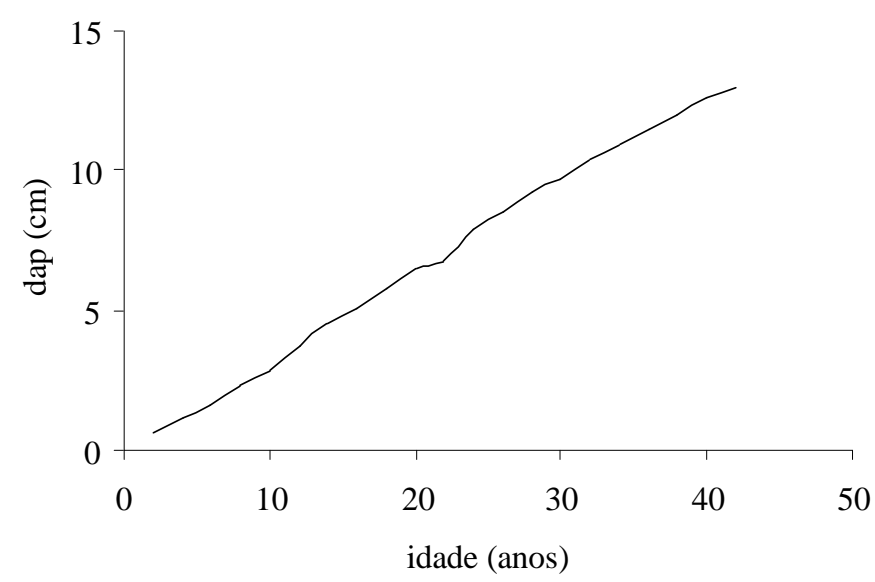

FIGURA 4: Desenvolvimento do DAP em função da idade, da caúna-da-serra.

No caso da espécie cocão os resultados estatísticos do ajuste dos modelos 1 a 5 são mostrados na Tabela 2 e nas Figuras 5 a 7. Na Figura 8, observa-se a relação diâmetro sobre idade na altura 1,3 $\mathrm{m}$. Também, com essa espécie, se observou um ajuste ótimo para o volume e o fator de forma comercial, como variável dependente, no modelo 3, segundo os critérios estabelecidos. $\mathrm{O}$ incremento em volume comercial anual percentual, que cai para $10 \%$ com o aumento do diâmetro, foi melhor ajustado com o modelo 1 (veja critérios dos modelos na Tabela 2). $\mathrm{O}$ fator de forma desenvolve-se de 0,3 para acima de 0,6. O DAP sobre a idade nos primeiros 40 anos segue uma reta. 
TABELA 2: Cocão - parâmetros estatísticos dos modelos estudados para estimar o volume comercial, o fator de forma comercial e o incremento volumétrico percentual em função do DAP (os modelos com melhor ajuste são marcados com asterisco).

\begin{tabular}{|c|c|c|c|c|c|c|}
\hline \multirow{2}{*}{$\begin{array}{c}\text { N. } \\
\text { mod. }\end{array}$} & \multirow[t]{2}{*}{ Variável dependente } & \multicolumn{3}{|c|}{ Coeficientes } & \multirow[t]{2}{*}{$\mathrm{R}^{2}$} & \multirow[t]{2}{*}{ Syx } \\
\hline & & $\mathrm{b}_{0}$ & $\mathrm{~b}_{1}$ & $\mathrm{~b}_{2}$ & & \\
\hline \multirow[t]{3}{*}{1} & $\mathrm{vol}_{\mathrm{c}}$ & 0,0001 & 2,3644 & & 0,9922 & 0,17595 \\
\hline & $\mathrm{ff}_{\mathrm{c}}$ & 0,1924 & 0,3644 & & 0,7501 & 0,17633 \\
\hline & ivol\% * & 104,31 & $-0,9208$ & & 0,9342 & 0,20425 \\
\hline \multirow[t]{3}{*}{2} & $\mathrm{vol}_{\mathrm{c}}$ & 0,0006 & 0,3353 & & 0,9029 & 0,62017 \\
\hline & $\mathrm{ff}_{\mathrm{c}}$ & 0,2246 & 0,0599 & & 0,9159 & 0,10230 \\
\hline & ivol\% & 60,4 & $-0,1366$ & & 0,8887 & 0,26565 \\
\hline \multirow[t]{3}{*}{3} & $\operatorname{vol}_{\mathrm{c}} *$ & 0,004 & $-0,0029$ & 0,0006 & 0,9994 & 0,00119 \\
\hline & $\mathrm{ff}_{\mathrm{c}}$ & 0,1905 & 0,0241 & 0,000007 & 0,9458 & 0,03314 \\
\hline & ivol\% & 83,555 & $-11,729$ & 0,432 & 0,7355 & 13,3086 \\
\hline \multirow[t]{3}{*}{4} & $\operatorname{vol}_{\mathrm{c}}$ & 0,0448 & $-0,0045$ & & 0,5996 & 0,03071 \\
\hline & $\mathrm{ff}_{\mathrm{c}}$ & 0,1441 & 0,1342 & & 0,7409 & 0,07143 \\
\hline & ivol\% & $-27,67$ & 78,953 & & 0,8217 & 10,7741 \\
\hline \multirow[t]{3}{*}{5} & $\mathrm{vol}_{\mathrm{c}}$ & 0,0082 & $-0,0337$ & & 0,897 & 0,01557 \\
\hline & $\mathrm{ff}_{\mathrm{c}} *$ & 0,0242 & 0,19 & & 0,9458 & 0,03269 \\
\hline & ivol\% & $-3,3932$ & 55,714 & & 0,5345 & 17,4099 \\
\hline
\end{tabular}

Em que: vol $_{\mathrm{c}}=$ volume comercial; $\mathrm{ff}_{\mathrm{c}}=$ fator de forma comercial; ivol $\%$ = incremento volumétrico percentual; $\mathrm{R}^{2}=$ coeficiente de determinação; Syx = erro-padrão da estimativa; $b_{0}, b_{1}, b_{2}=$ coeficientes angulares.

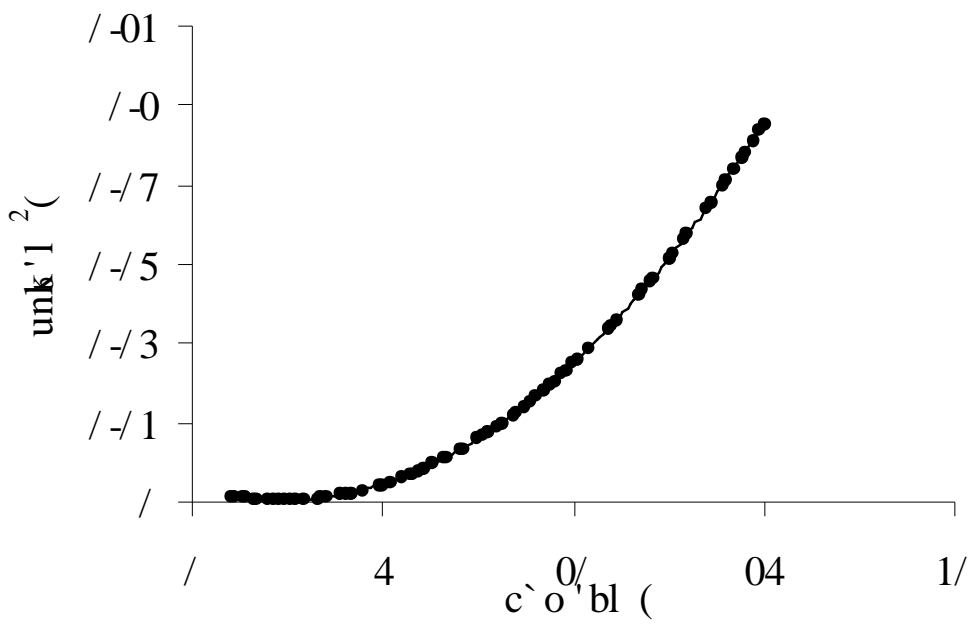

FIGURA 5: Desenvolvimento do volume comercial (vol ${ }_{c}$ ) em função do DAP, do cocão. 


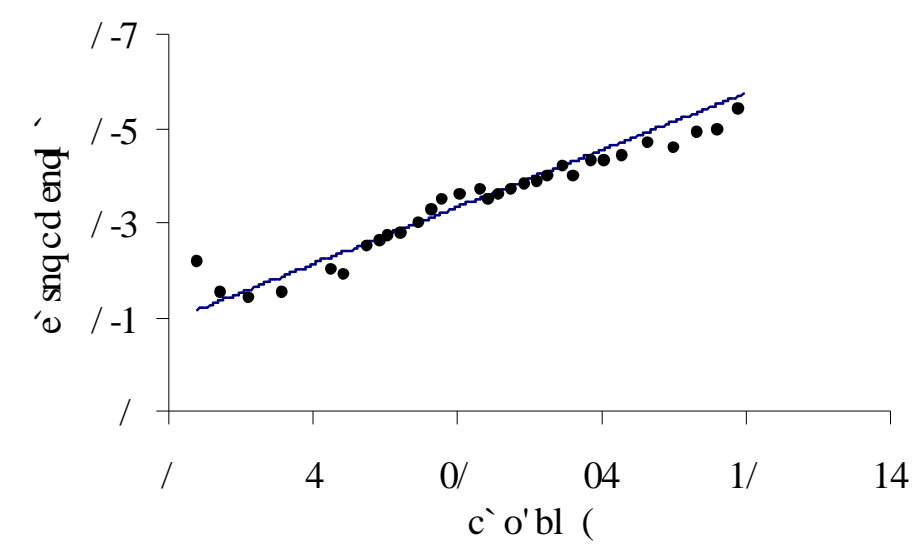

FIGURA 6: Desenvolvimento do fator de forma comercial em função do DAP, do cocão.

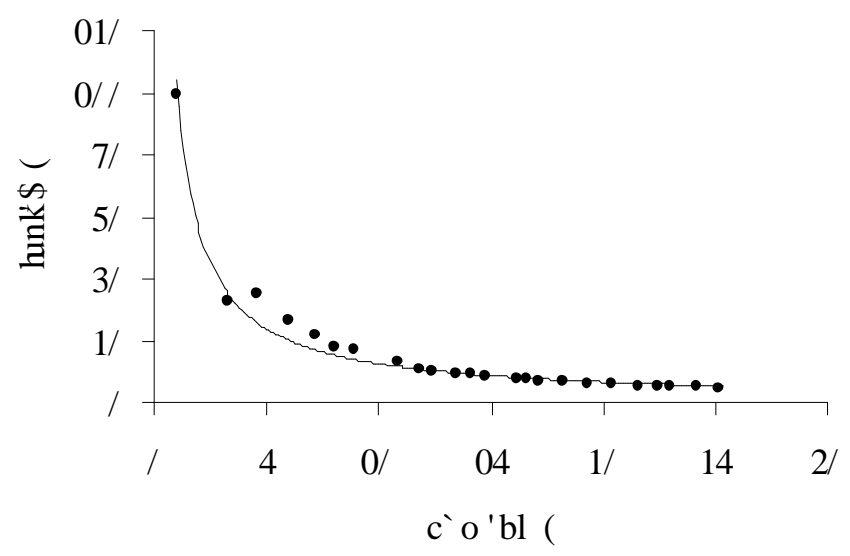

FIGURA 7: Desenvolvimento do incremento em volume comercial anual percentual (ivol) em função do DAP, do cocão.

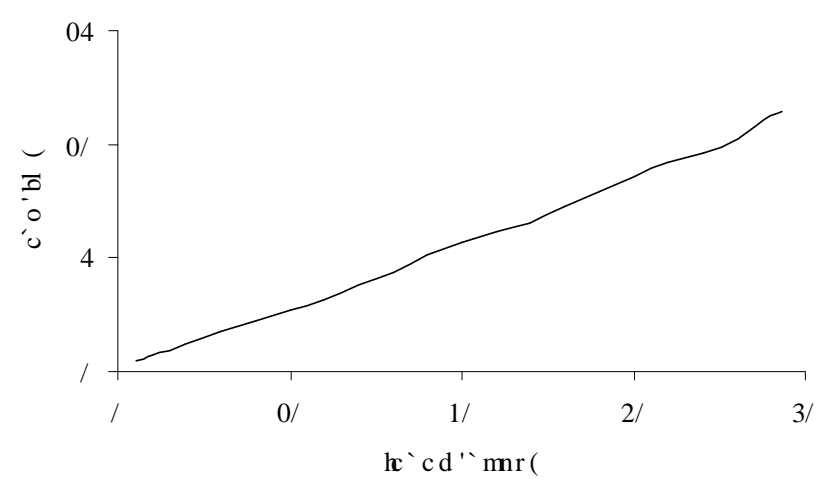

FIGURA 8: Desenvolvimento do DAP em função da idade, do cocão. 
TABELA 3: Tarumã-de-espinho - parâmetros estatísticos dos modelos estudados para estimar o volume comercial, o fator de forma comercial e o incremento volumétrico percentual em função do DAP (os modelos com melhor ajuste são marcados com asterisco).

\begin{tabular}{|c|c|c|c|c|c|c|}
\hline \multirow{2}{*}{$\begin{array}{c}\text { N. } \\
\text { mod. }\end{array}$} & \multirow[t]{2}{*}{ Variável dependente } & \multicolumn{3}{|c|}{ Coeficientes } & \multirow[t]{2}{*}{$\mathrm{R}^{2}$} & \multirow[t]{2}{*}{ Syx } \\
\hline & & $\mathrm{b}_{0}$ & $\mathrm{~b}_{1}$ & $\mathrm{~b}_{2}$ & & \\
\hline \multirow[t]{3}{*}{1} & $\operatorname{vol}_{\mathrm{c}}$ & 0,0005 & 2,017 & & 0,982 & 0,22613 \\
\hline & $\mathrm{ff}_{\mathrm{c}}$ & 0,4329 & 0,271 & & 0,8932 & 0,05680 \\
\hline & ivol\% $*$ & 144,34 & $-1,0457$ & & 0,8812 & 0,31693 \\
\hline \multirow[t]{3}{*}{2} & vol $_{\mathrm{c}}$ & 0,003 & 0,2131 & & 0,984 & 0,54627 \\
\hline & $\mathrm{ff}_{\mathrm{c}}$ & 0,6133 & 0,0231 & & 0,8608 & 0,06487 \\
\hline & ivol\% & 59,844 & $-0,1174$ & & 0,8704 & 0,33091 \\
\hline \multirow[t]{3}{*}{3} & $\operatorname{vol}_{\mathrm{c}} *$ & 0,0047 & $-0,0028$ & 0,0007 & 0,9992 & 0,00347 \\
\hline & $\mathrm{ff}_{\mathrm{c}} *$ & 0,4961 & 0,0362 & $-0,0006$ & 0,9337 & 0,03666 \\
\hline & ivol\% & 86,014 & $-9,2903$ & 0,2544 & 0,875 & 8,27689 \\
\hline \multirow[t]{3}{*}{4} & $\operatorname{vol}_{c}$ & 0,114 & $-0,1399$ & & 0,6072 & 0,07567 \\
\hline & $\mathrm{ff}_{\mathrm{c}}$ & 0,220 & 0,315 & & 0,901 & 0,04422 \\
\hline & ivol\% & $-26,173$ & 81,991 & & 0,8729 & 8,24297 \\
\hline \multirow[t]{3}{*}{5} & $\mathrm{vol}_{\mathrm{c}}$ & 0,0156 & $-0,0852$ & & 0,9244 & 0,03320 \\
\hline & $\mathrm{ff}_{\mathrm{c}}$ & 0,0191 & 0,5924 & & 0,9026 & 0,04387 \\
\hline & ivol\% & $-2,4672$ & 53,315 & & 0,6081 & 14,4716 \\
\hline
\end{tabular}

Em que: vol $_{\mathrm{c}}=$ volume comercial; $\mathrm{ff}_{\mathrm{c}}=$ fator de forma comercial; ivol\% = incremento volumétrico percentual; $\mathrm{R}^{2}=$ coeficiente de determinação; Syx $=$ erro-padrão da estimativa; $b_{0}, b_{1}, b_{2}=$ coeficientes angulares.

O tarumã-de-espinho revelou maior fator de forma do que as primeiras duas espécies estudadas por causa da acumulação de volume com aumento do DAP ser maior. A forma quase-cilíndrica do tronco deve-se à influência de galhos de grandes dimensões na altura da inserção da copa. O desenvolvimento do diâmetro em função da idade a altura de 1,3 m é ilustrado na Figura 12, mostrando a forma de reta. Revelou-se o mesmo padrão de ótimo ajuste com o volume comercial e o fator de forma comercial (modelo 3) e o incremento em volume comercial anual percentual (modelo 1) (Tabela 3 e Figura 9 a 11).

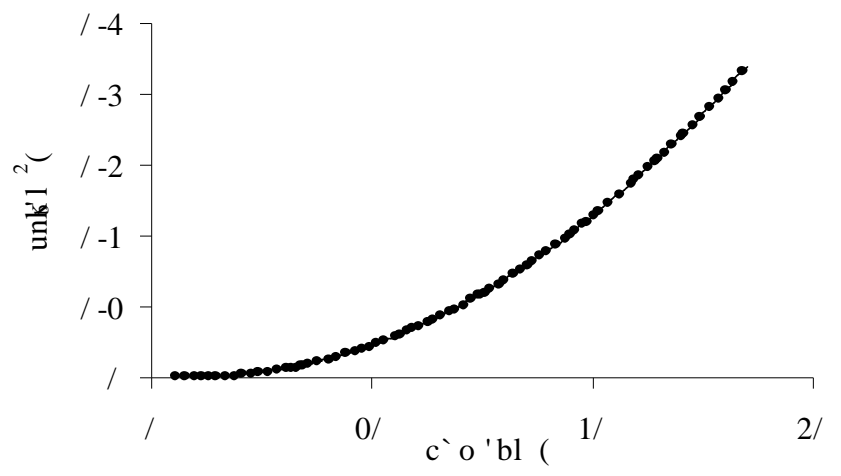

FIGURA 9: Desenvolvimento do volume comercial ( $\operatorname{vol}_{c}$ ) em função do DAP, do tarumã. 


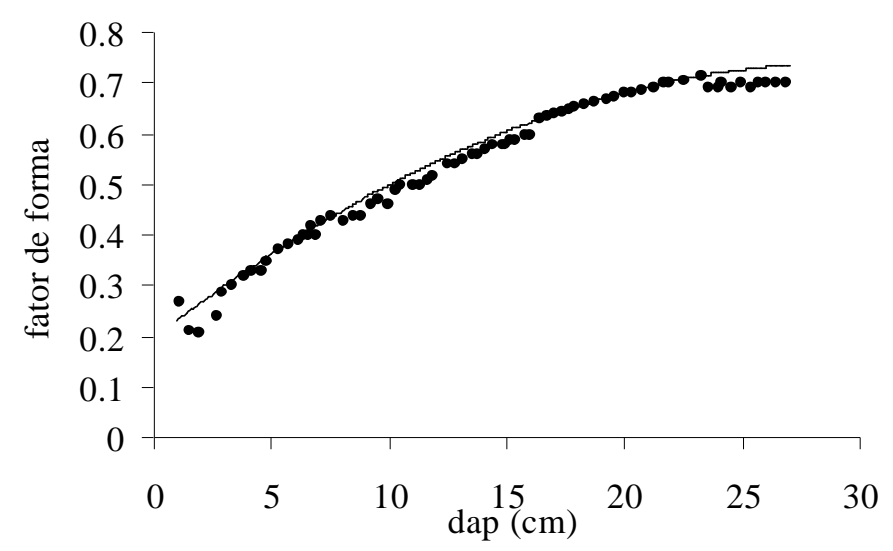

FIGURA 10: Desenvolvimento do fator de forma comercial em função do DAP, do tarumã.

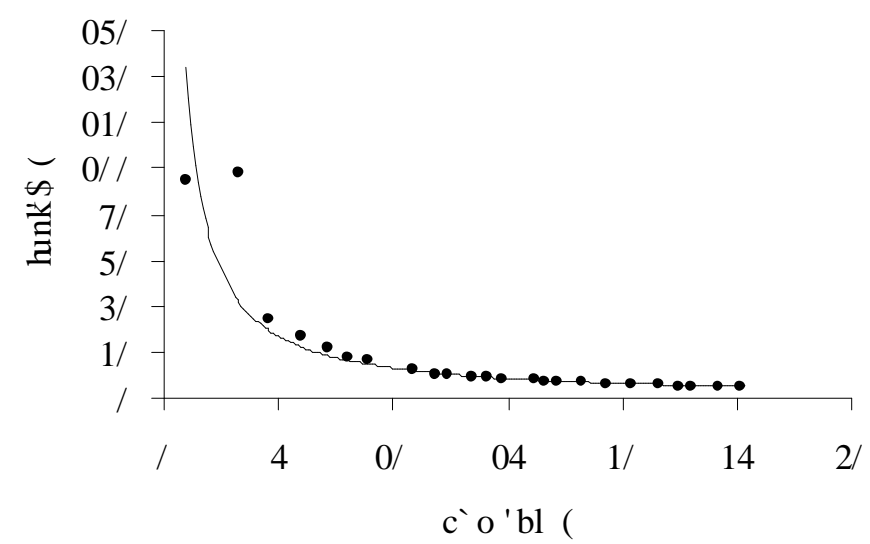

FIGURA 11: Desenvolvimento do incremento em volume comercial anual percentual (ivol) em função do DAP, do tarumã.

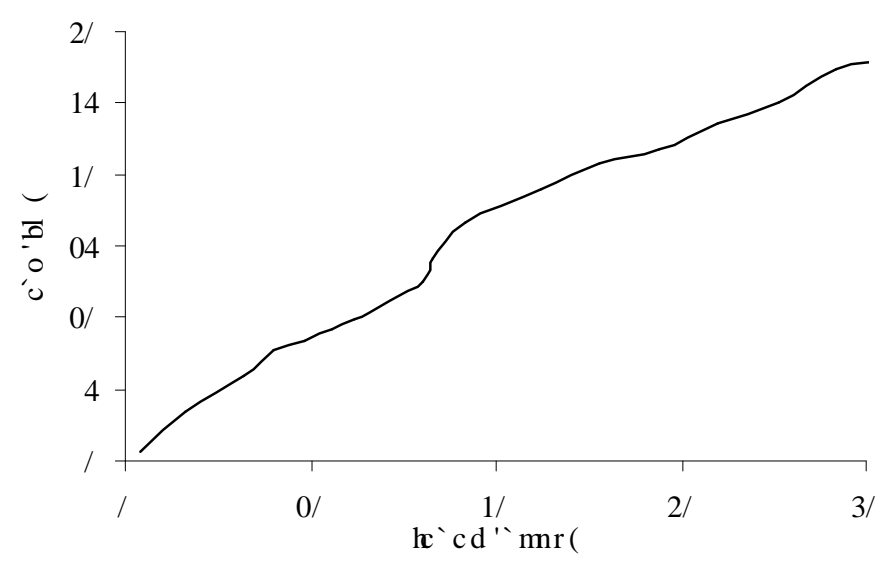

FIGURA 12: Desenvolvimento do DAP em função da idade, do tarumã. 
Como nas três espécies anteriores, a capororoca mostrou o mesmo padrão de ajuste no volume comercial e fator de forma comercial (modelo 3) e incremento em volume comercial anual percentual (modelo 1) (veja Tabela 4 e Figura 13-15). Também com a capororoca, um fator de forma mais cilíndrica foi achado, o que significa uma acumulação maior em volume sobre o DAP. Na Figura 16, observa-se a relação diâmetro e idade à altura do peito.

TABELA 4: Capororoca - parâmetros estatísticos dos modelos estudados para estimar o volume comercial, o fator de forma comercial e o incremento volumétrico percentual em função do DAP (os modelos com melhor ajuste são marcados com asterisco).

\begin{tabular}{|c|c|c|c|c|c|c|}
\hline \multirow{2}{*}{$\begin{array}{c}\text { N. } \\
\text { mod. }\end{array}$} & \multirow[t]{2}{*}{ Variável dependente } & \multicolumn{3}{|c|}{ Coeficientes } & \multirow[t]{2}{*}{$\mathrm{R}^{2}$} & \multirow[t]{2}{*}{ Syx } \\
\hline & & $\mathrm{b}_{0}$ & $\mathrm{~b}_{1}$ & $\mathrm{~b}_{2}$ & & \\
\hline \multirow[t]{3}{*}{1} & $\mathrm{vol}_{\mathrm{c}}$ & 0,0002 & 2,0862 & & 0,9957 & 0,10784 \\
\hline & $\mathrm{ff}_{\mathrm{c}}$ & 0,4643 & 0,1869 & & 0,8521 & 0,04854 \\
\hline & ivol\% * & 583,38 & $-1,4079$ & & 0,9661 & 0,20911 \\
\hline \multirow[t]{3}{*}{2} & $\operatorname{vol}_{c}$ & 0,003 & 0,1717 & & 0,85 & 0,64250 \\
\hline & $\mathrm{ff}_{\mathrm{c}}$ & 0,6257 & 0,0119 & & 0,636 & 0,07616 \\
\hline & ivol\% & 119,22 & $-0,123$ & & 0,8902 & 0,37642 \\
\hline \multirow[t]{3}{*}{3} & $\operatorname{vol}_{\mathrm{c}} *$ & $-0,0026$ & $3 \mathrm{E}-05$ & 0,0003 & 0,9988 & 0,00368 \\
\hline & $\mathrm{ff}_{\mathrm{c}} *$ & 0,4691 & 0,0317 & $-0,0007$ & 0,9099 & 0,02693 \\
\hline & ivol\% & 227,86 & $-22,736$ & 0,5374 & 0,7032 & 38,2731 \\
\hline \multirow[t]{3}{*}{4} & $\mathrm{vol}_{\mathrm{c}}$ & 0,1036 & $-0,1486$ & & 0,6394 & 0,06158 \\
\hline & $\mathrm{ff}_{\mathrm{c}}$ & 0,1316 & 0,4204 & & 0,8648 & 0,03243 \\
\hline & ivol\% & $-76,862$ & 237,56 & & 0,7791 & 32,4670 \\
\hline \multirow[t]{3}{*}{5} & $\operatorname{vol}_{\mathrm{c}}$ & 0,0112 & $-0,0719$ & & 0,9419 & 0,02472 \\
\hline & $\mathrm{ff}_{\mathrm{c}}$ & 0,0085 & 0,6277 & & 0,6677 & 0,05084 \\
\hline & ivol\% & $-5,0112$ & 120,75 & & 0,3998 & 53,5135 \\
\hline
\end{tabular}

Em que: vol $_{\mathrm{c}}=$ volume comercial; $\mathrm{ff}_{\mathrm{c}}=$ fator de forma comercial; ivol $\%=$ incremento volumétrico percentual; $\mathrm{R}^{2}=$ coeficiente de determinação; Syx $=$ erro-padrão da estimativa; $b_{0}, b_{1}, b_{2}=$ coeficientes angulares.

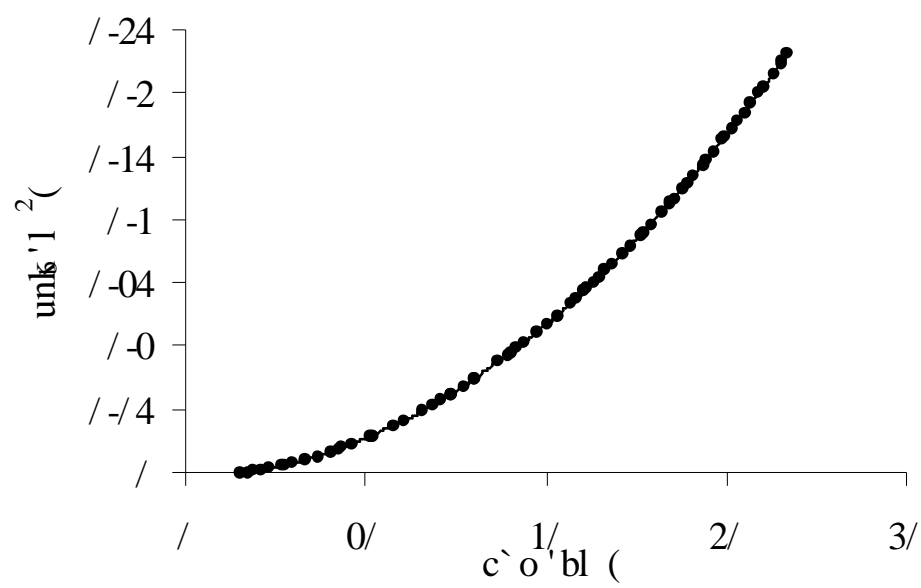

FIGURA 13: Desenvolvimento do volume comercial ( $\operatorname{vol}_{\mathrm{c}}$ ) em função do DAP, da capororoca. 


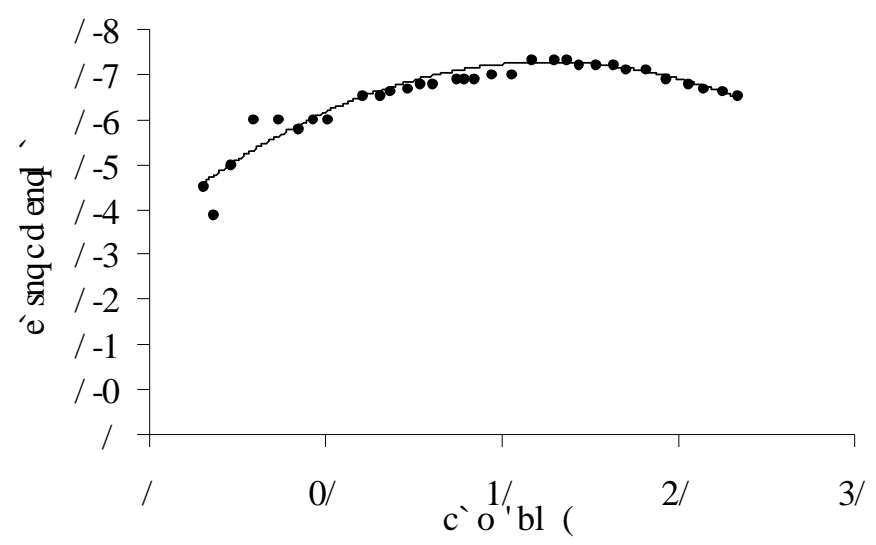

FIGURA 14: Desenvolvimento do fator de forma comercial em função do DAP, da capororoca.

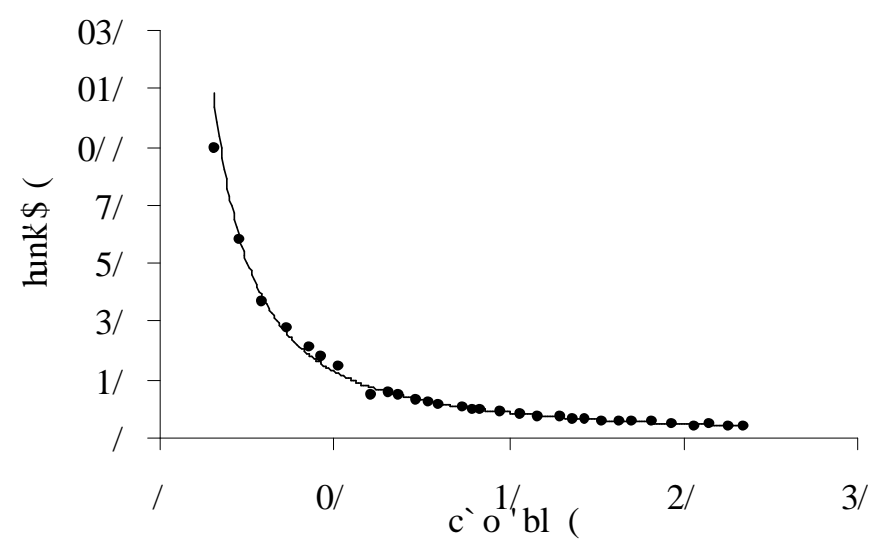

FIGURA 15: Desenvolvimento do incremento em volume comercial anual percentual (ivol) em função do DAP, da capororoca.

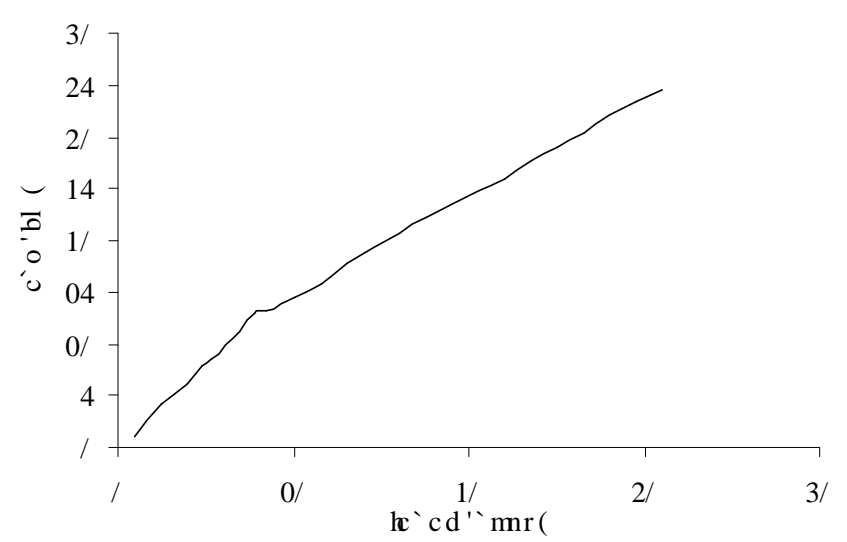

FIGURA 16: Desenvolvimento do DAP em função da idade, da capororoca. 
A análise de covariância mostrou desigualdade do crescimento em volume (modelo escolhido: 3) entre as espécies. Portanto, não é possível adotar um modelo só para as espécies estudadas (Tabela 5, Figura 17).

TABELA 5: Análise de covariância.

\begin{tabular}{l|c|c|c|c|c}
\hline FV & GL & SQ & QM & F & Prob>F \\
\hline DAP & 1 & 0,002 & 0,002 & 4,642 & 0,0328 \\
DAP & 1 & 0,0808 & 0,0808 & 186,0 & 0,0000 \\
Espécie & 3 & 0,0795 & 0,0265 & 60,99 & 0,0000 \\
\hline
\end{tabular}

Em que: FV = Fonte da variação; $\mathrm{GL}=$ Graus de liberdade; $\mathrm{SQ}=$ Soma dos quadrados; $\mathrm{QM}=$ Quadrado Médio; $\mathrm{F}=$ Estatística F de Snedecor.

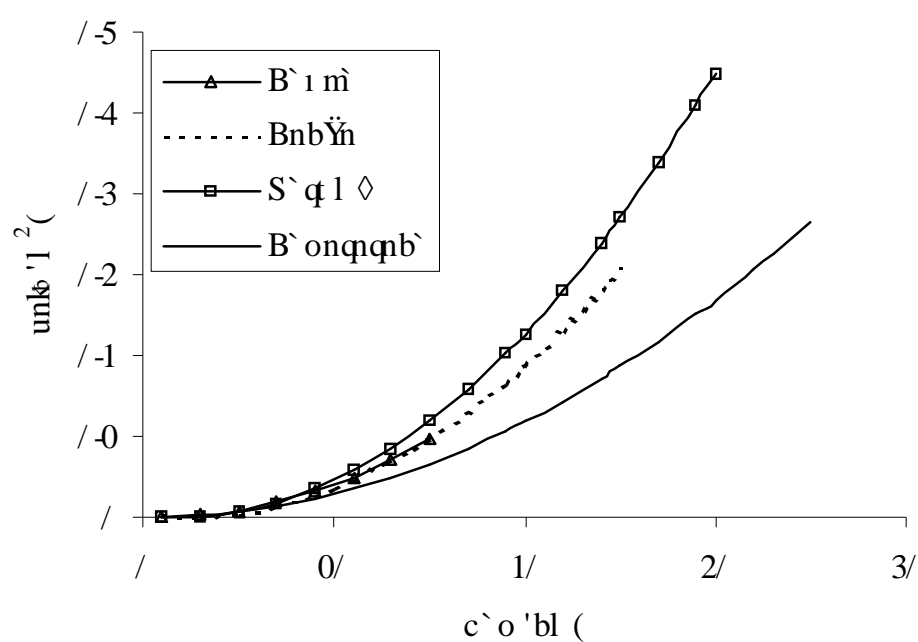

FIGURA 17: Desenvolvimento do volume comercial ( $v_{c} l_{c}$ em função do DAP, das espécies estudadas.

\section{CONCLUSÕES}

Os resultados do presente trabalho permitiram concluir, para as espécies estudadas, que:

Há viabilidade da técnica de análise de tronco para avaliar o crescimento das espécies em florestas subtropicais sob influência de estacionalidade (formação de anéis anuais);

Ocorre um melhor ajuste matemático do desenvolvimento do volume comercial e do fator de forma com um polinômio de segundo grau em todos os casos com excepção do cocão em que uma função linear mostrou melhor ajuste;

Ocorre um melhor ajuste matemático do incremento em volume comercial anual percentual com uma função de potência;

Os fatores de forma comercial variam entre 0,2 e 1, sendo que as duas últimas espécies 
apresentaram um tronco mais cilíndrico;

$\mathrm{O}$ incremento anual percentual em volume comercial apresenta uma tendência exponencial negativa, estabelecendo-se em todos os casos estudados abaixo de 10\%;

Não é possível adotar um modelo só do crescimento em volume para as espécies estudadas.

\section{REFERÊNCIAS BIBLIOGRÁFICAS}

AMARAL JUNIOR, A. Flora ilustrada catarinense: Eritroxiláceas. Itajaí: Herbário Barbosa Rodrigues, 1980. $64 \mathrm{p}$.

CARVALHO, P.E.R. Espécies florestais brasileiras, recomendações silviculturais, potencialidades e uso da madeira. Brasilia: Embrapa/CNPF, 1994. 640 p.

EDWIN, G., REITZ, R. Flora ilustrada catarinense: aquifoliáceas. Itajaí: Herbário Barbosa Rodrigues, 1967.

FINGER, C.A.G. Fundamentos da biometria florestal. Santa Maria: UFSM/CEPEF/FATEC, 1992. 269 p.

LAMPRECHT, H. Silvicultura nos trópicos. Eschbom: GTZ, 1990, 343p.

LONGHI, S.J.; VACCARO, S.; BUENO COELHO, M.C. et al. Análise fitosociológica de um remanescente de floresta ombrófila mista em Itaára, Santa Maria - RS: SIMPÓSIO SOBRE ECOSSISTEMAS NATURAIS DO MERCOSUL, 1., 1996, Santa Maria. Anais... Santa Maria, 1996. p. 79-89.

MAIXNER, A.E., FERREIRA, L.A.B. Contribuição ao estudo das essências florestais e frutíferas nativas no Rio Grande do Sul. Trigo e Soja, v. 28, p. 2-27, 1978.

MITSCHERLICH, G. Der Fichten-Tannen-(Buchen)-Plenterwald. Schriftenr. Bad. Forstl. Versuchsanstalt, Freiburg i. Br., v. 8, p. 3-42, 1952.

MOREnO, J.A. Clima do Rio Grande do Sul. Porto Alegre: Secretaria da Agricultura-RS, 1961. $41 \mathrm{p}$.

REITZ, R.; KLEIN, R.M.; REIS, A. Projeto madeira do Rio Grande do Sul. Porto Alegre: CORAG, 1988. $525 \mathrm{p}$.

SANCHOTENE, M. Frutíferas nativas úteis à fauna na arborização urbana. Porto Alegre: FEPLAM, $1985.311 \mathrm{p}$.

SCHULZ, O.E. Erythroxylaceae. In: Engler. Das Pflanzenreich, 1907. p. 1-176.

SOBRAL, M. Erythroxylum no Rio Grande do Sul, Brasil. Porto Alegre: UFRGS, 1990. $41 \mathrm{p}$.

VACCARO, S.; LONGHI, S.J. Análise fitossociológica de algumas áreas remanescentes da floresta do Alto Uruguay, entre os rios de Ijuí e Turvo, no Rio Grande do Sul. Ciência Florestal, v. 5, p. 33-54, 1995.

ZEIDE, B. Analysis of growth equations. Forest Science, v. 39, n. 3, p. 594-616, 1993. 